\title{
Dependence of survival on growth in larval pollock Pollachius virens and haddock Melanogrammus aeglefinus: a field study based on individual hatchdates
}

\author{
Louis Fortier ${ }^{1, *}$, Casimiro Quiñonez-Velazquez ${ }^{2}$ \\ ${ }^{1}$ GIROQ, Département de biologie, Université Laval, Ste-Foy, Québec G1K 7P4, Canada \\ ${ }^{2}$ CICIMAR, Departemento de Pesquerías y Biología Marina, Playa El Conchalito s/n, PO Box 592, La Paz 23000 , \\ Baja California Sur, México
}

\begin{abstract}
The hatchdate frequency distributions (HFD) of pollock and haddock larvae sampled at monthly intervals west of Sable Island (Scotian Shelf, northwest Atlantic) in 1992 and 1993 were reconstructed for different age intervals $(0-20,21-40,41-80 \mathrm{~d})$ and corrected for aliasing due to sampling discontinuity and mortality-dispersion. The ratio of the HFD at a given age to the HFD at an earlier age was used as an index of the relative survival of larvae grouped into $5 \mathrm{~d}$ hatchdate cohorts. Pollock hatched from November to March and haddock from February to June. In pollock, seasonal variations in relative survival of the cohorts over the 21-40 and 41-80 d age intervals were correlated to strong variations in growth. In haddock, growth varied little over the hatching season and there was no significant link with survival. For pollock, slow growth invariably resulted in low survival but fast growth resulted in either low or high survival, indicating that fast growth is a necessary but not sufficient condition for survival. Increased predation pressure late in the hatching season of both species could explain the decoupling of growth and survival in cohorts hatched in spring and early summer
\end{abstract}

KEY WORDS: Fish larvae - Growth - Survival - Pollock · Haddock

\section{INTRODUCTION}

Fish that hatch at different times during the spawning season of a species will face different conditions in the plankton, with different probabilities of survival. The hatchdate of fish larvae and juveniles sampled at sea can be determined through the enumeration of daily increments in the otolith (Methot 1983). By comparing the hatchdate frequency distribution (HFD) of fish surviving to a given developmental stage to the seasonal production of eggs or newly hatched larvae, it is possible to identify potential 'survival windows' within the season of reproduction (Methot 1983, Victor 1983, Crecco \& Savoy 1985, Rice et al. 1987, Checkley et al. 1988, Nyman \& Conover 1988, Yoklavich \& Bailey 1990, Amara et al. 1995). The comparison of biotic or

•E-mail: louis.fortier@bio.ulaval.ca abiotic conditions that prevailed within and outside survival windows can be a powerful tool to test current hypotheses on recruitment determination (e.g. Campana \& Jones 1992, Moksness \& Fossum 1992). For example, the match/mismatch (Cushing 1990) and growth-predation (Anderson 1988) hypotheses predict that fast-growing larvae will survive better than slowgrowing larvae because they remain vulnerable to their planktonic predators for a shorter period of time. This prediction can be tested by comparing the growth of fish larvae which hatched within and outside survival windows in the HFD.

A first assumption of the HFD approach is that the same population of young fish is sampled through time. On the Scotian Shelf (northwest Atlantic), the eggs, larvae and pelagic juveniles of pollock Pollachius virens and haddock Melanogrammus aeglefinus are retained for several months over the slope of banks 
west of Sable Island (Gagné \& O'Boyle 1984, O'Boyle et al. 1984). Residual circulation on the Scotian Shelf is from the northeast to the southwest (e.g. Sutcliffe et al. 1976). There is no haddock spawning and little pollock spawning north and east of Sable Island (O'Boyle et al. 1984) and, therefore, the component of the population retained over the banks west of Sable Island is likely of local origin. This population can be repeatedly sampled through time, using different types of gear to capture the different developmental stages (Suthers \& Frank 1989, Meekan \& Fortier 1996, Chaumillon \& Fortier in press).

A second assumption of the HFD approach is that survival is compared among larvae of the same age that have been exposed to the agents of mortality in the plankton for a similar extent of time (Yoklavich \& Bailey 1990, Campana \& Jones 1992). Fish which hatched close to the time of collection will have experienced less cumulative mortality than fish which hatched earlier. The resulting over-representation of recently hatched fish in the HFD can be corrected by reducing the abundance of late cohorts in proportion to the mortality they would have suffered during the time interval needed to reach the age of early hatchers (Yoklavich \& Bailey 1990, Campana \& Jones 1992).

A third assumption of the approach is that the probability that a fish which hatched on a given date will be sampled at a given age and, therefore, be represented in the HFD of a given age interval is independent of the temporal distribution of sampling effort. Unless sampling is continuous, some larvae which hatched on certain dates will necessarily be non-vulnerable to sampling during some age interval. Given that sampling at sea is usually discontinuous, HFDs must be corrected for this aliasing.

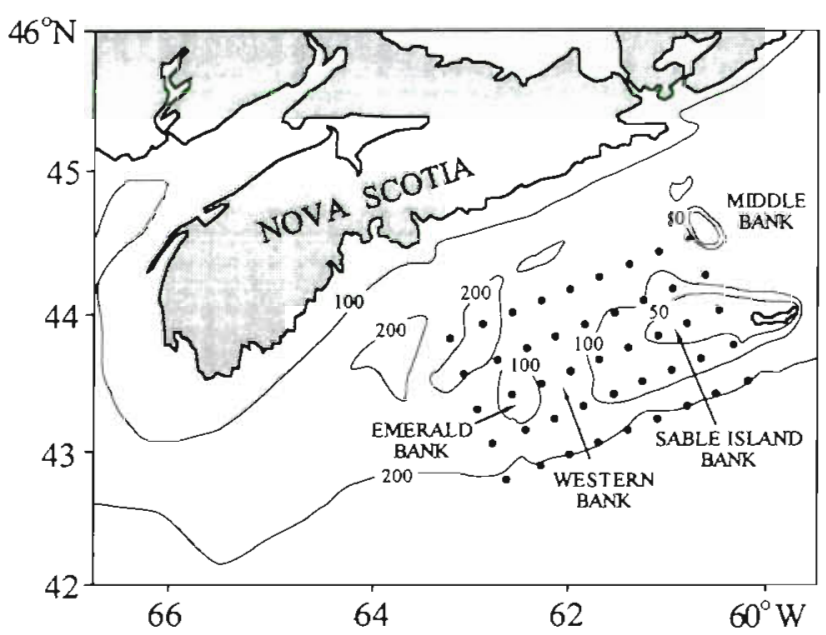

Fig. 1 Scotian Shelf showing the location of the 45 station sampling grid west of Sable Island. Isobaths are in $\mathrm{m}$
In the present study, the HFDs of larval pollock and haddock sampled west of Sable Island (Scotian Shelf) in 1992 and 1993 were reconstructed for different age intervals $(0-20,21-40,41-80$ d) and corrected for aliasing due to mortality-dispersion and to the temporal distribution of sampling. This is equivalent to the sequential sampling approach proposed by Campana \& Jones (1992). Larvae which hatched within 5 d intervals were grouped into cohorts. The ratio of the HFD at a given age to the HFD at an earlier age was used as an index of relative survival among $5 \mathrm{~d}$ cohorts produced at different times during the spawning season. We tested the hypothesis that high survival is linked to fast growth by comparing relative survival and average growth among cohorts.

\section{MATERIALS AND METHODS}

Sampling. Fish larvae and pelagic juveniles were sampled monthly from August 1991 to May 1993 over a grid of 45 stations covering Emerald, Western and Sable Island banks (Fig. 1). On average, the sampling grid was covered in 5 consecutive days in the third week of the month. Details of sampling methodology are given in Meekan \& Fortier (1996) and Chaumillon \& Fortier (in press). In summary, weather permitting, a rectangular midwater trawl (RMT), equipped with nets of $2 \mathrm{~m}^{2}$ (333 $\mu \mathrm{m}$ mesh) and $8 \mathrm{~m}^{2}$ (1600 $\mu \mathrm{m}$ mesh) in effective mouth aperture, was deployed at each station of the grid in a multiple-oblique cast from the surface to $75 \mathrm{~m}$ (or to $5 \mathrm{~m}$ from the bottom at stations $<75 \mathrm{~m}$ deep), at a speed of 2.0 to 2.5 knots ( 1 to $1.25 \mathrm{~m} \mathrm{~s}^{-1}$ ) for $17 \pm 5$ min (mean $\pm \mathrm{SD}$ ). Temperature, salinity, depth, pitch, filtered volume and filtering efficiency were monitored in real time. In March 1993, following the failure of the main winch, the RMT was replaced by a lighter rectangular frame supporting two $1 \mathrm{~m}^{2}$ square nets (250 and $333 \mu \mathrm{m}$ mesh sizes). Independent CTD casts were made at each station where the rectangular sampler was deployed in March 1993

In addition to the RMT, a multi-net sampler (Eastern Marine Services E-Z-Net) mounted with 9 identical nets ( $1 \mathrm{~m}^{2}$ aperture, $333 \mu \mathrm{m}$ mesh) was used to determine the vertical distribution of fish larvae at the grid station where the highest density of fish larvae (not necessarily pollock or haddock larvae) was found with the RMT. Casts were made at intervals of ca 4 h over at least $24 \mathrm{~h}$ to characterize diel migration patterns. On each cast, adjacent $5 \mathrm{~m}$ depth intervals were sampled for $5 \mathrm{~min}$, from $45 \mathrm{~m}$ (or less if the selected station was shallower than $45 \mathrm{~m}$ ) to the surface. Although the vertical distributions are not presented here, the larvae collected with the multi-net sampler were used in the present analysis. 
Avoidance of the samplers was assessed by comparing the length frequency distribution of larvae captured by day and by night. Fish larvae perceive light in the 400 to $700 \mathrm{~nm}$ wavelength band (Blaxter 1975) and the threshold intensity below which visual perception is reduced lies in the range 50 to 1000 lux (e.g. Blaxter 1986), corresponding to 1-20 $\mu \mathrm{mol}$ photons $\mathrm{m}^{-2} \mathrm{~s}^{-1}$. Hourly values of total incident irradiance at Sable Island (Fig. 1) were supplied by Environment Canada and transformed into light intensity in the 400 to $700 \mathrm{~nm}$ range following Thimijan \& Heins (1983). Samples collected at intensities $<20 \mu \mathrm{mol}$ photons $\mathrm{m}^{-2} \mathrm{~s}^{-1}$ (400 to $700 \mathrm{~nm}$ wavelength band) were classified as night collections. The length frequency distribution and the range of length of pollock and haddock larvae captured by day and by night were similar and we found no strong evidence of avoidance for either species (Fig. 2).

Length, age and hatchdate. A large fraction of the 3420 pollock (46\%) and 1990 haddock (65\%) larvae sampled in the 2 years were sorted on the ship and preserved in $95 \%$ ethanol. Small larvae that escaped detection at sea were preserved in $4 \%$ buffered formalin and sorted later in the laboratory. A subset of pollock and haddock were videotaped at sea before preservation in ethanol. In the laboratory, fish preserved in ethanol were measured to the nearest $0.1 \mathrm{~mm}$. For each species, the regressions between fresh standard length (SL) (obtained from the videotape) and standard length after preservation in ethanol were used to calculate the fresh standard length of larvae preserved in ethanol. The length of larvae preserved in formalin was corrected for shrinkage using the time interval between preservation and measurement, following Hjörleifsson \& Klein-MacPhee (1992).

Up to 3 larvae of each species in every $1 \mathrm{~mm} \mathrm{SL}$ length class were selected at random from each station for age determination. The sagittae and lapilli of 532 pollock and 422 haddock larvae $<36 \mathrm{~mm}$ SL were dissected under polarized light and mounted in Permount on glass slides. The sagittae were read at the Southwest Fisheries Center (La Jolla, CA, USA) using an image analyzer consisting of a video camera attached to a microscope, a monitor, a digitizer, and a microcomputer (Andersen \& Moksness 1988). Growth increments were counted twice by the same reader at an interval of 3 mo. The 2 counts usually differed by less than $6 \%$ and the average was used as an estimate of age. The age of the remaining fish (mostly small larvae $<10 \mathrm{~mm}$ ) was estimated using separate age-length keys (Kimura 1977) for each sampling survey. The hatchdates of individual fish were calculated by subtracting age from date of capture.

Our interpretation of otolith structure and the daily nature of increment deposition were validated using 9

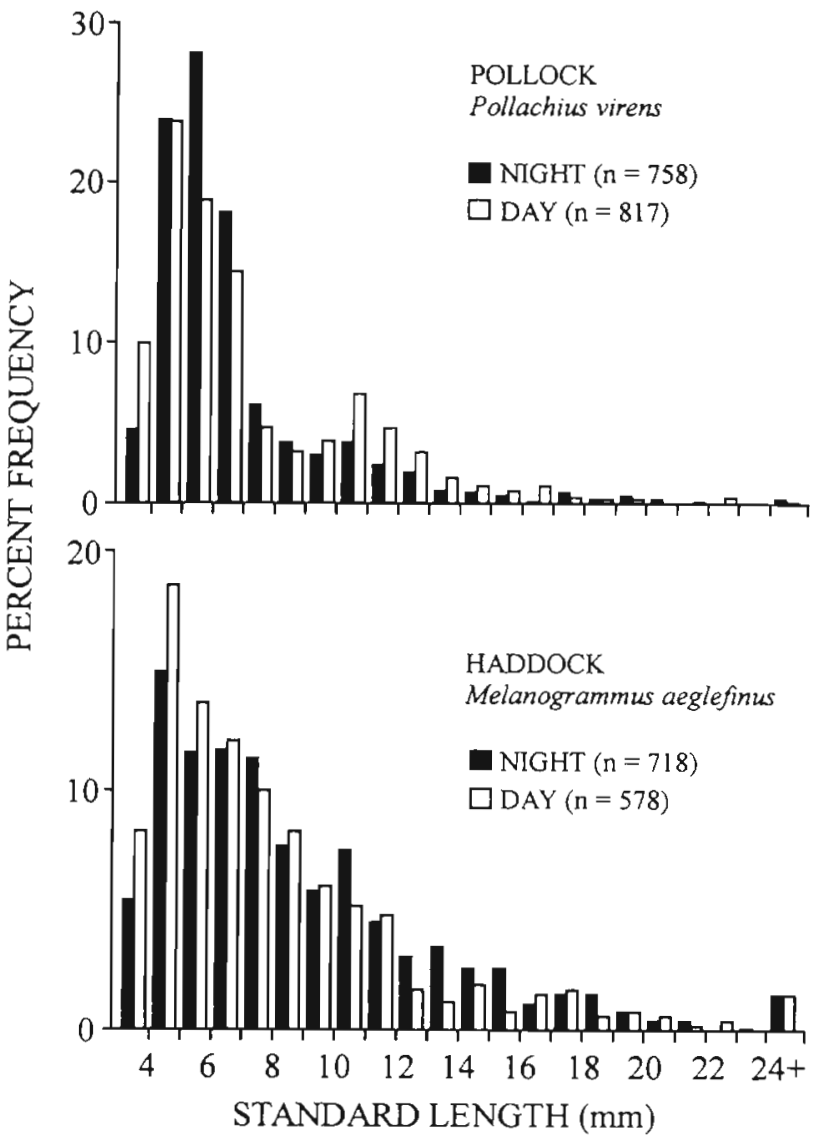

Fig. 2. Length frequency distribution of pollock Pollachius virens and haddock Melanogrammus aeglefinus larvae sampled by day (incident light in the 400 to $700 \mathrm{~nm}$ range $>20$ $\mu \mathrm{mol}$ photon $\mathrm{m}^{-2} \mathrm{~s}^{-1}$ ) and by night (incident light $<20 \mu \mathrm{mol}$ photon $\mathrm{m}^{-2} \mathrm{~s}^{-1}$ ). Rectangular midwater trawl and multi-net samples combined

pollock and 136 haddock larvae of known age which hatched from eggs collected with the $333 \mu \mathrm{m}$ mesh net of the RMT and incubated on the ship. Immediately after the nets were brought on board, eggs at the most advanced stage of development were sorted from the codend and individually put in $20 \mathrm{~mm}$ vials filled with seawater filtered through Whatman GF/F filters (nominal pore size $0.7 \mu \mathrm{m}$ ). Eggs were reared at $4^{\circ} \mathrm{C}$ in a refrigerator on the ship. A $12 \mathrm{~h}$ dark/12 h light photoperiod was maintained using dim blue light. The eggs were checked twice a day to establish hatching time with a maximum error of $12 \mathrm{~h}$. Pollock larvae 10 to $4 \mathrm{~d}$ old) and haddock larvae (0 to $11 \mathrm{~d}$ old) were sacrificed and preserved in $95 \%$ ethanol. In the laboratory, the sagittae of each larva were mounted as above and analyzed by the same age reader using an image analyzer system (Optimas system) similar to the one described above.

In pollock otolith, the nucleus was surrounded occasionally by 2 prominent increments. The outer incre- 
ment was stronger and was assumed to represent the hatch check (Radtke \& Waiwood 1980, Bolz \& Lough 1983. Campana 1989). In haddock, 1 to 3 irregular increments were present between the nucleus and the hatch check in some otoliths, as observed by Bolz \& Lough (1983). The mean $( \pm \mathrm{SD})$ diameter of the hatch check of reared larvae was $20.7 \pm 2.2 \mu \mathrm{m}$ in pollock and $21.4 \pm 3.3 \mu \mathrm{m}$ in haddock. The latter value is consistent with earlier reports for haddock (Bolz \& Lough 1983. Campana 1989). Post-hatch check increments appeared as alternate light and dark zones and the first regular increment was formed the day after hatching in both species. The number of increments after the hatch check (NI) corresponded well to the chronological age in $d$ (AGE) of the larvae. The slopes of the regressions for pollock ( $\mathrm{NI}=1.09 \mathrm{AGE}, \mathrm{n}=9, \mathrm{r}^{2}=0.82$, $\mathrm{p}=0.0005)$ and haddock (NI $=0.99 \mathrm{AGE}, \mathrm{n}=146, \mathrm{r}^{2}=$ $0.96, p>0.0001$ ) did not differ significantly from 1 ( $t$-test, $p=0.890$ for pollock and $p=0.637$ for haddock $)$.

Correction of HFDs for aliasing due to mortalitydispersion and sampling discontinuities. Fish larvae hatched within $5 \mathrm{~d}$ intervals (starting on 5 November for pollock and 10 February for haddock) were grouped into cohorts and the absolute frequency (number of larvae) of each $5 \mathrm{~d}$ cohort was calculated. For each species, uncorrected HFDs were reconstructed for all larvae, and for larvae in the age intervals $0-20,21-40$ and $41-80 \mathrm{~d}$.

A rough estimate of the rate of loss of larvae by mortality and/or dispersion out of the sampling area was obtained from the regression of abundance (overall number captured) on age. For a given age interval (e.g. $0-20,21-40,41-80 \mathrm{~d}$ old), the over-representation of late hatchers in the HFD (sensu Yoklavich \& Bailey 1990, Campana \& Jones 1992) was corrected by reducing the abundance of each $5 \mathrm{~d}$ cohort in proportion to the average mortality and dispersion the larvae would have suffered during the interval between the average age of the larvae in the $5 \mathrm{~d}$ cohort and the upper boundary of the age interval considered. For example, if the average age of larvae within a given $5 \mathrm{~d}$ cohort of the HFD of pollock $21-40 \mathrm{~d}$ of age at capture was $27 \mathrm{~d}$. the number of larvae in that cohort was reduced in proportion to the percent loss these larvae would have experienced over the age interval 27 to $40 \mathrm{~d}$ (based on the mortality-dispersion curves described above).

The different periods during which fish larvae in different age intervals $(0-20,21-40$ and $41-80 \mathrm{~d}$ old) were vulnerable to our sampling were calculated from survey dates. For example, pollock larvae 21-40 d old were vulnerable to the 17-25 February 1992 survey only if they hatched within the period 8 January ( 17 February minus $40 \mathrm{~d}$ of age) to 4 February 1992 (25 February minus $21 \mathrm{~d}$ of age). Gaps in the HFD corresponding to windows of non-vulnerability were filled by fitting 1 (or 2) continuous normal (Gaussian) distribution to the uncorrected HFD and extrapolating the missing frequencies (number of larvae) from the fitted distribution (see Figs. $3 \& 6$ for an example).

The corrected HFDs of the different age intervals were standardized by transforming the absolute frequency of each cohort into relative frequency (i.e. dividing the number of larvae in a cohort by the total number of larvae in the HFD). The relative survival of a $5 \mathrm{~d}$ cohort was defined as the ratio of its relative frequency in the HFD of an age interval to its relative frequency in the HFD of the previous age interval (Crecco \& Savoy 1985). This index of relative survival is equivalent to survival indices based on the frequency distribution of back-calculated growth rates in fish sampled at different stages in their ontogeny (Healey 1982, Hovenkamp 1992, Meekan \& Fortier 1996)

To compare relative survival to growth, an age-independent index of the growth performance of each larva was defined. For each species, the standard length of all aged larvae for the 2 years was plotted against age, and the upper limit (fitted by eye) of the resulting envelope was used as an estimate of the maximum potential length that the species could achieve at a given age, under the environmental conditions prevailing in the 2 years of sampling. The growth perfor mance of a larva of a given age was defined as the ratio of its standard length to maximum potential length at age multiplied by 100 . The percentage of the maximum potential growth achieved by each larva was then averaged for each $5 \mathrm{~d}$ hatch cohort and used as an index of the cumulative growth performance of this cohort at the end of a given growth interval.

\section{RESULTS}

\section{Uncorrected hatchdate frequency distributions}

Pollock hatched from 5 November to 24 March in the winter 1991-1992 and from 5 December to 15 March in the winter 1992-1993 (Fig. 3a, b). The overall (all larvae) raw HFD followed a relatively flattened normal distribution in 1991-1992 (Fig. 3a) but was much more contracted in time in the winter 1992-1993 (Fig. 3b). Gaps in the uncorrected HFD of pollock for the age intervals $0-20$ and $21-40 \mathrm{~d}$ corresponded well to periods of non-vulnerability to our sampling; a result that confirms the accuracy of the aging procedure (Fig. 3c-f). In the winter 1991-1992, all cohorts of larvae in the age interval $41-80 \mathrm{~d}$ were vulnerable to our sampling at some time and no gap was obvious in the HFD (Fig. 3g). Too few (14) pollock larvae 41-80 d of age were aged to assess the HFD of this age interval in the winter 1992-1993. 

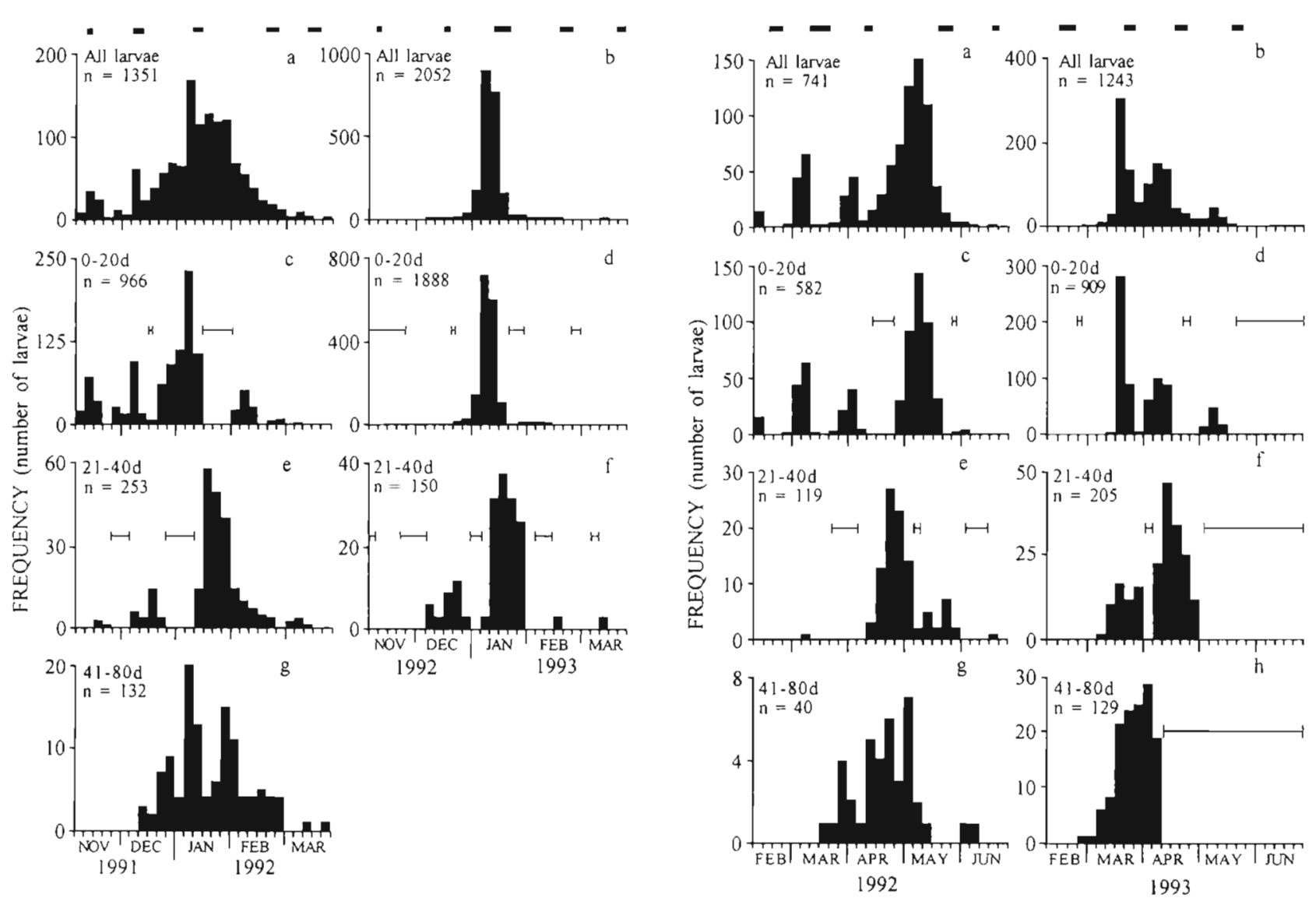

Fig. 3. Pollachius virens. Uncorrected hatchdate frequency distribution (HFD) of pollock larvae sampled at monthly intervals in the winters 1991-1992 and 1992-1993. HFDs were reconstructed for all larvae and for larvae in the intervals $0-20,21-40$ and 41-80 d old at capture. Thick horizontal bars: effective sampling periods durng the season of hatch. Range bars: periods of non-vulnerability of larvae in a given age interval to our sampling

Haddock hatched from 10 February to 19 June 1992 and from 25 February to the end of our sampling on 21 May 1993 (Fig. 4a, b). As for pollock, gaps in the HFD of larvae for the $0-20$ and $21-40 \mathrm{~d}$ age intervals coincided well with periods of non-vulnerability to our sampling (Fig. 4c-f). In 1993, the HFDs of the 21-40 and 41-80 d age intervals were truncated by the end of our sampling (Fig. 4f, h).

\section{HFDs corrected for mortality-dispersion and sampling discontinuity}

In both species, abundance at age declined rapidly and the rate of decline decreased with age (Fig. 5). Obvious anomalies in the declining trend suggested that some ages (e.g. 10-20 d for pollock) were poorly sampled. Yet, a large fraction ( $86 \%$ for each species) of

Fig. 4. Melanogrammus aeglefinus. Uncorrected HFD of haddock larvae sampled at monthly intervals in 1992 and 1993. HFDs were reconstructed for all larvae and for larvae in the intervals $0-20,21-40$ and $41-80$ d old at capture. Thick horizontal bars: effective sampling periods during the season of hatch. Range bars: periods of non-vulnerability of larvae in a given age interval to our sampling

the variance in abundance at age was explained by the models fitted to the data and these were used to estimate average losses by mortality and/or dispersion in order to correct the HFDs.

The abundance of each $5 \mathrm{~d}$ cohort was reduced in proportion to the losses that the larvae would have suffered (based on the mortality-dispersion curves in Fig. 5) during the interval between the average age of the $5 \mathrm{~d}$ cohort and the upper boundary of the age interval considered. Given the high loss rates (Fig. 5), the corrections were often important, especially in $5 \mathrm{~d}$ cohorts with low average age (Figs. $6 \&$ 7).

For each age interval, a normal (Gaussian) continuous distribution was fitted to the HFDs corrected for mortality-dispersion (2 normal distributions were fitted in the case of haddock in the age interval $0-20 \mathrm{~d}$ in 1992) (Figs. 6 \& 7). Gaps in the HFD due to sampling discontinuity were filled with the abundance predicted by the fitted normal distribution. 

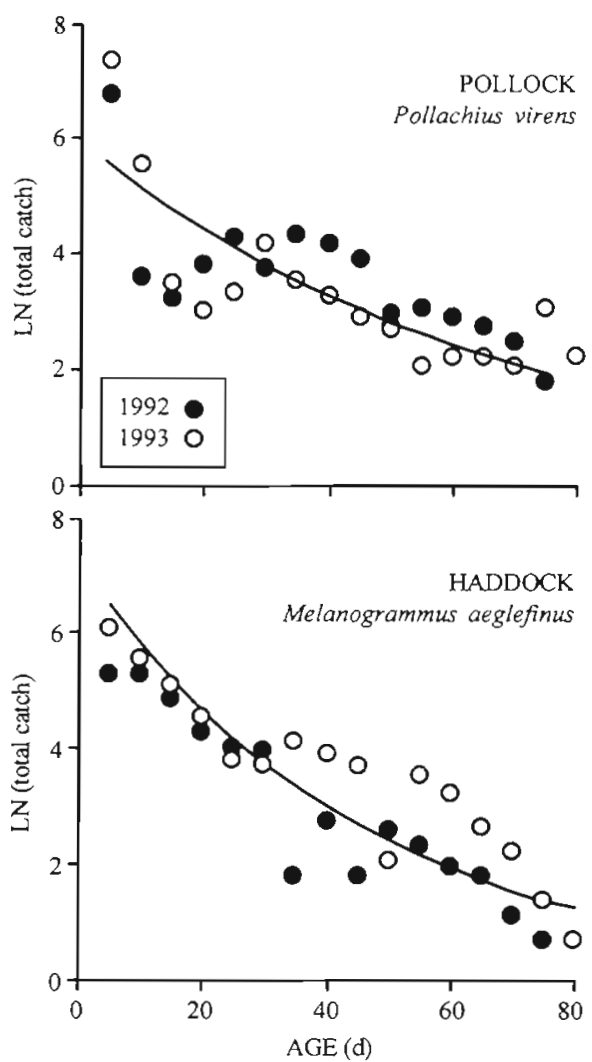

Fig. 5. Total catch at age for pollock Pollachius virens and haddock Melanogrammus aeglefinus larvae sampled at monthly intervals from 1991 to 1993 . For pollock: In(total catch $)=6.45 \mathrm{e}^{-0.015 \mathrm{AGE}}, \mathrm{r}^{2}=0.86$; for haddock: $\ln ($ total catch $)=$ $7.25 \mathrm{e}^{-0022 A G E}, \mathrm{r}^{2}=0.86$

In pollock, the seasonal span of the corrected HFDs changed during ontogeny. In the winter 1991-1992, early cohorts (5 November to 10 December) progressively disappeared and late cohorts ( 8 February to $24 \mathrm{March}$ ) became better represented during development from newly hatched and first feeding stages $(0-20 \mathrm{~d}$ age interval) to late pelagic stages $(41-80 \mathrm{~d}$ of age) (Fig. 6a-c). In the winter 1992-1993, the HFD of pollock larvae $0-20 \mathrm{~d}$ of age at capture was narrow. with the bulk of hatching taking place between late December and late January (Fig. 6d). The HFD flattened and spread over the season as both early and late cohorts became better represented in the $21-40 \mathrm{~d}$ age interval (Fig. 6e).

In haddock in 1992, the early cohorts of February and March and the strong median cohorts of May detected in the corrected HFD of the $0-20 \mathrm{~d}$ age interval were poorly represented in that of the $21-40 \mathrm{~d}$ age interval (Fig. $7 a$, b). Fish which hatched from late March to early May were well represented in the HFD of the 41-80 d age interval (Fig. $7 \mathrm{c}$ ). In 1993, the cor-

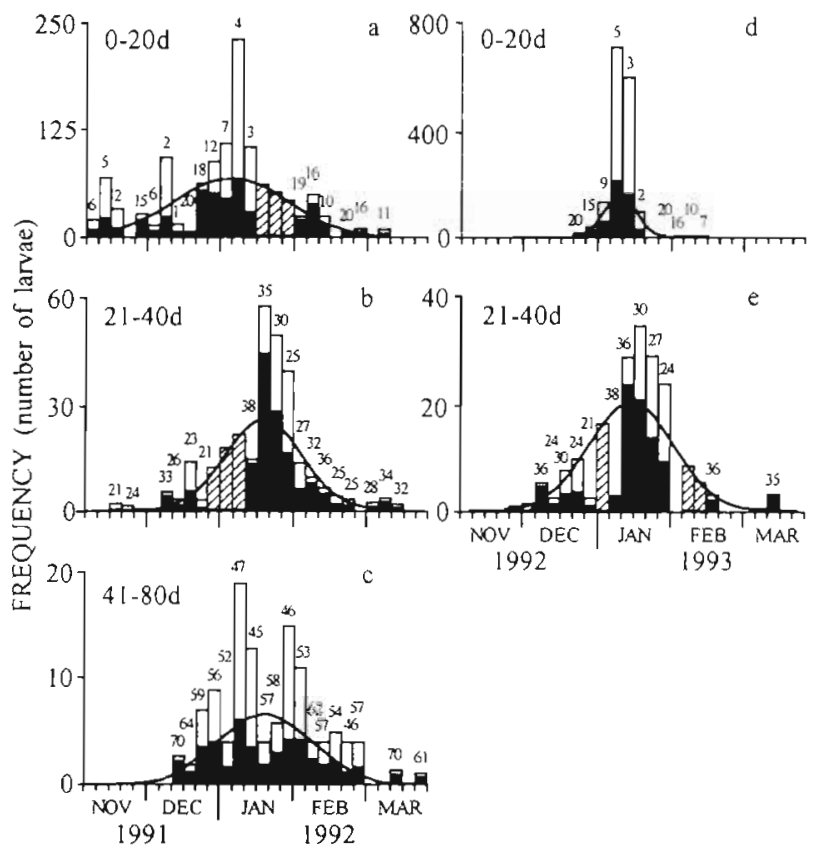

Fig. 6. Pollachius virens. Uncorrected (sum of black and white histograms) and corrected (black histograms) HFDs of pollock larvae sampled at monthly intervals in the winters 1991-1992 and 1992-1993. HFDs were reconstructed for larvae in the intervals $0-20,21-40$ and $41-80 \mathrm{~d}$ old at capture and corrected for mortality-dispersion by reducing the abundance of each $5 \mathrm{~d}$ cohort in proportion to the loss the larvae would have suffered during the period between the average age of the cohort at capture (given above each histogram) and the upper limit of the age interval considered (see text and Fig. 5). Normal curves fitted to the data were used to interpolate frequencies for periods of non-vulnerability to our sampling (hatched histograms)

rected HFDs of successive age intervals were relatively stable, with abundant hatch cohorts in late March and early April persisting in the truncated HFD of the $21-40 \mathrm{~d}$ age interval and that of the $41-80 \mathrm{~d}$ age interval (Fig. $7 \mathrm{~d}-\mathrm{f})$.

\section{Growth and relative survival}

Standard length at age was more variable in pollock larvae than in haddock larvae, especially during the first 40 d of development (Fig. 8). For example, over the age interval 1 to $35 \mathrm{~d}$, the standard deviation in length calculated for each day of age averaged $0.89 \mathrm{~mm}$ $(12.3 \%$ of the mean) for pollock larvae and $0.53 \mathrm{~mm}$ $(7.2 \%)$ for haddock. Over that age interval, individual pollock larvae only half the length of the longest larvae of the same age were commonly observed, whereas haddock larvae presented a much narrower range in length at age (Fig. 8). 


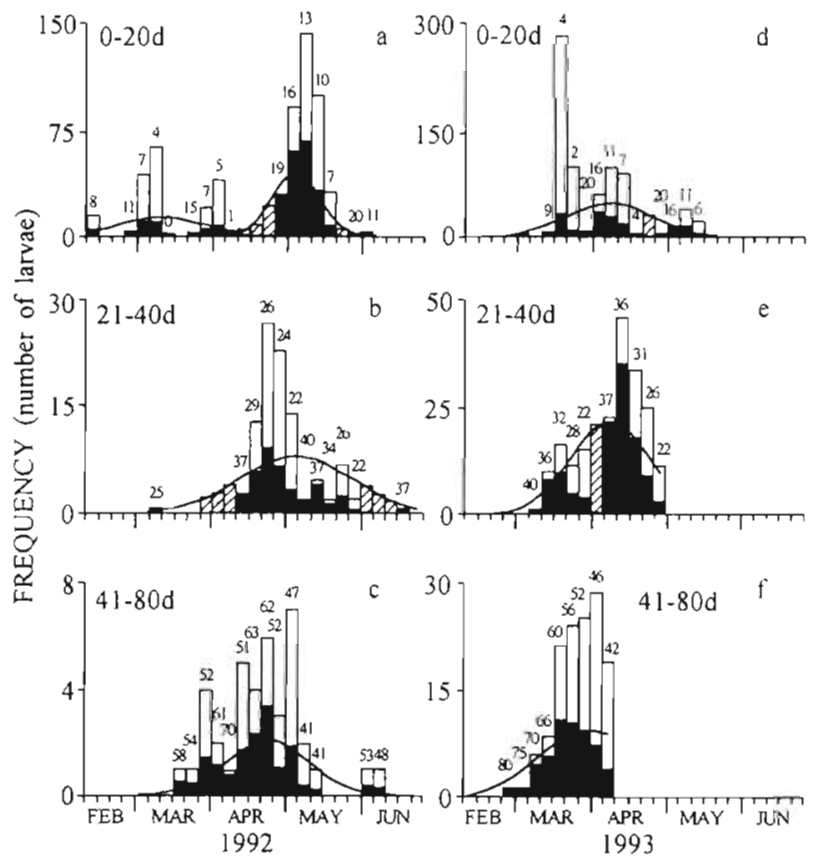

Fig. 7 Melanogrammus aeglefinus. Uncorrected (sum of black and white histograms) and corrected (black histograms) HFDs of haddock larvae sampled at monthly intervals in 1992 and 1993. HFDs were reconstructed and corrected for mortality-dispersion as explained in Fig. 6 legend. Normal curves fitted to the data were used to interpolate frequencies for periods of non-vulnerability to our sampling (hatched histograms)

Our index of relative survival ranged from 0 (cohort absent in the HFD of the oldest age interval and present in the HFD of the youngest age interval) to $+\infty$ (cohort represented in the HFD of the oldest age interval but absent in the youngest age interval, resulting in a division by 0 ). In most cases when a division by zero did not occur, the value of the survival index was $<6$, as reported in other studies (Crecco \& Savoy 1985, Hovenkamp 1992, Meekan \& Fortier 1996). Relative survival values in the range 6 to $+\infty$ were assigned a numerical value of 6 in the figures and were excluded from statistical analyses.

In pollock, relative survival was often (but not always) proportional to growth. In the winter 1991-1992, relative survival between 21 and 40 d of age paralleled growth performance for cohorts hatched early in the season (15 November to 29 January): low survival in November and December coincided with weak growth performance, whereas high survival in January corresponded to good growth performance (Fig. 9a). For these early cohorts, the correlation between survival and growth was weak but statistically significant (arcsine-transformed variables, regression weighted by the number of larvae in each cohort represented by at least 3 larvae, $\mathrm{n}=8$ cohorts, $\left.\mathrm{r}^{2}=0.52, \mathrm{p}<0.05\right)$. The positive correlation between survival and growth did not hold in February and March, when low survival corresponded to good growth performance for 4 of the 5 cohorts (Fig. 9a). Relative survival over the interval 41-80 d of age was significantly correlated to growth performance $\left(n=15\right.$ cohorts, $\left.r^{2}=0.41, p<0.001\right)$. Relatively high survival in December and February corresponded to good growth performance, whereas poor survival in January coincided with low growth performance (Fig, 9b).

In the winter 1992-1993, relative survival of pollock from $21 \mathrm{~d}$ to $40 \mathrm{~d}$ of age was often infinite (division by zero) as cohorts represented in the HFD of the $21-40 \mathrm{~d}$ age interval were absent from the HFD of the $0-20 \mathrm{~d}$ age interval (Fig. 9c). In addition, estimates of the average growth performance were often based on a limited number of larvae. Therefore, any inference regarding the link between survival and growth in that year cannot be supported with statistical analyses. In general, both relative survival and growth performance were high and varied little over the hatching season (Fig. 9c).

The overall relationship between survival and growth was illustrated by plotting relative survival

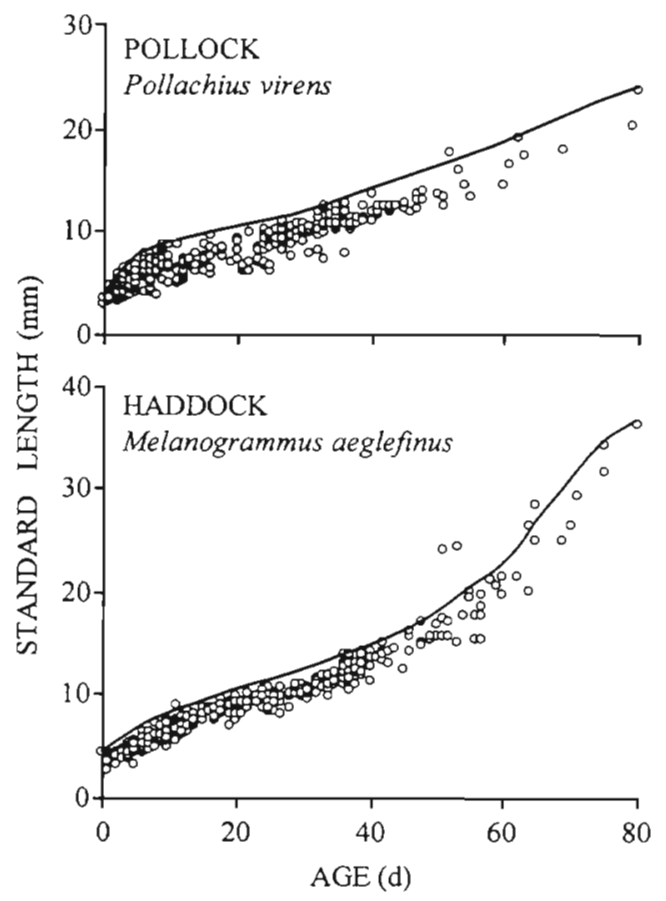

Fig. 8. Standard length at age of pollock Pollachius virens $(\mathrm{n}=$ 532 ) and haddock Melanogrammus aeglefinus ( $n=422)$ sampled at monthly intervals from 1991 to 1993. Each point may represent several larvae. Upper limit of the point envelope (thick line fitted by eye) represents the maximum length at age used to calculate the growth performance of each larva (individual standard length/maximum length for a given age) 

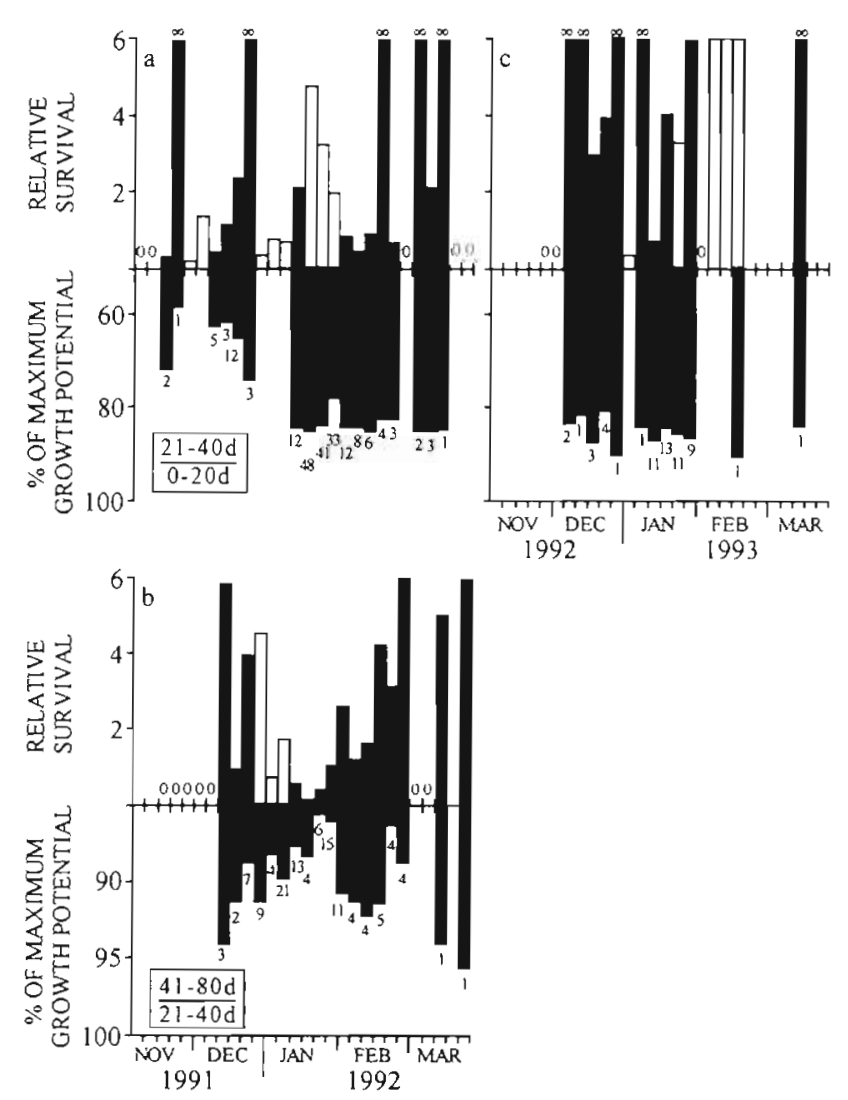

Fig. 9. Pollachius virens. Relative survival (ratio of cohort frequencies in successive age intervals) and average growth performance of $5 \mathrm{~d}$ hatch cohorts of pollock larvae sampled at monthly intervals in the winters 1991-1992 and 1992-1993. Infinite relative survival (cohort present in oldest age interval and absent in youngest) was given a value of 6 and is indicated by $\infty$. Null survival (as opposed to no estimate of survival) is indicated by 0 . Open histograms: estimates of survival in which hatchdate frequencies for the numerator or the denominator or both were interpolated from normal curves fitted to the corrected HFDs (see Figs. 6 \& 7). Average growth performances are for the oldest age interval and are plotted upside down to facilitate comparison with the survival estimates. Number under the histogram represents the number of larvae measured. Note that too few (14) larvae in the age interval 41-80 d were sampled in the winter 1992-1993 to calculate relative survival

against average growth performance for all $5 \mathrm{~d}$ hatch cohorts in both sampling years (Fig. 10). Relative survival between 21 and $40 \mathrm{~d}$ of age was always low at low growth performance but was either high or low at high growth performance (Fig. 10a). Relative survival between 41 to $80 \mathrm{~d}$ of age was low at low growth performance and generally high at high growth performance (Fig. 10b). Much scatter, which can be attributed to uncertainties in the estimates of both survival and growth, was present in the relationships. Some of this noise in the actual observations was filtered out by using the ratio of the normal curves fitted to the observed HFDs (Fig. 6), instead of the observed HFDs themselves, to calculate relative survival. The relationships between modeled relative survival and growth performance confirmed that survival from 21 to $40 \mathrm{~d}$ of age was low at low growth performance and variable at high growth performance (Fig. 10c). Survival from 41 to $80 \mathrm{~d}$ of age tended to increase with growth performance (Fig. 10d).

In haddock, little connection was found between survival and growth. In 1992, relative survival between 21 and $40 \mathrm{~d}$ of age often had to be estimated from the fitted normal curves as the cohort for a given $5 \mathrm{~d}$ hatch interval was often not represented in either the HFD of the $0-20$ or the 21-40 d age interval (Fig. 11a). The relatively high growth performance varied little among cohorts and there was no obvious link between survival and growth. For the 41 to $80 \mathrm{~d}$ survival interval, both relative survival and growth declined rapidly from mid March to mid April, but low survival in late April and May coincided with good growth performance (Fig. 11b). In 1993, variations in relative survival from 21 to $40 \mathrm{~d}$ of age appeared independent of the low growth performance (Fig. 11c). Estimates of relative survival from 41 to $80 \mathrm{~d}$ and of growth performance were available for larvae hatched during the period 25 February to 11 April only (Fig. 11d). Both

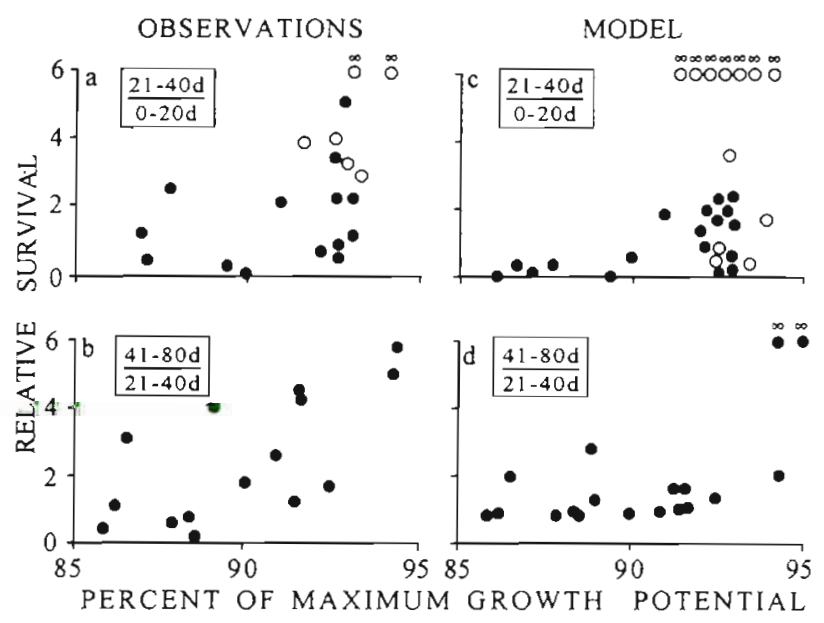

Fig. 10. Pollachius virens. Relative survival between successive age intervals as a function of average growth performance for $5 \mathrm{~d}$ hatch cohorts of pollock larvae sampled at monthly intervals in the winters 1991-1992 (-) and 1992-1993 (O). Relative survival was calculated from observed frequencies $(a, b)$ and from normal curves fitted to the observed frequencies ( $c$, d) (see text). Infinite relative survival (cohort present in oldest age interval and absent in youngest) was given a value of 6 and is indicated by $\infty$. Only those observations (i.e. cohorts) represented by at least 3 larvae are plotted. Note that too few (14) larvae in the age interval 41-80 d were sampled in the winter 1992-1993 to calculate relative survival 

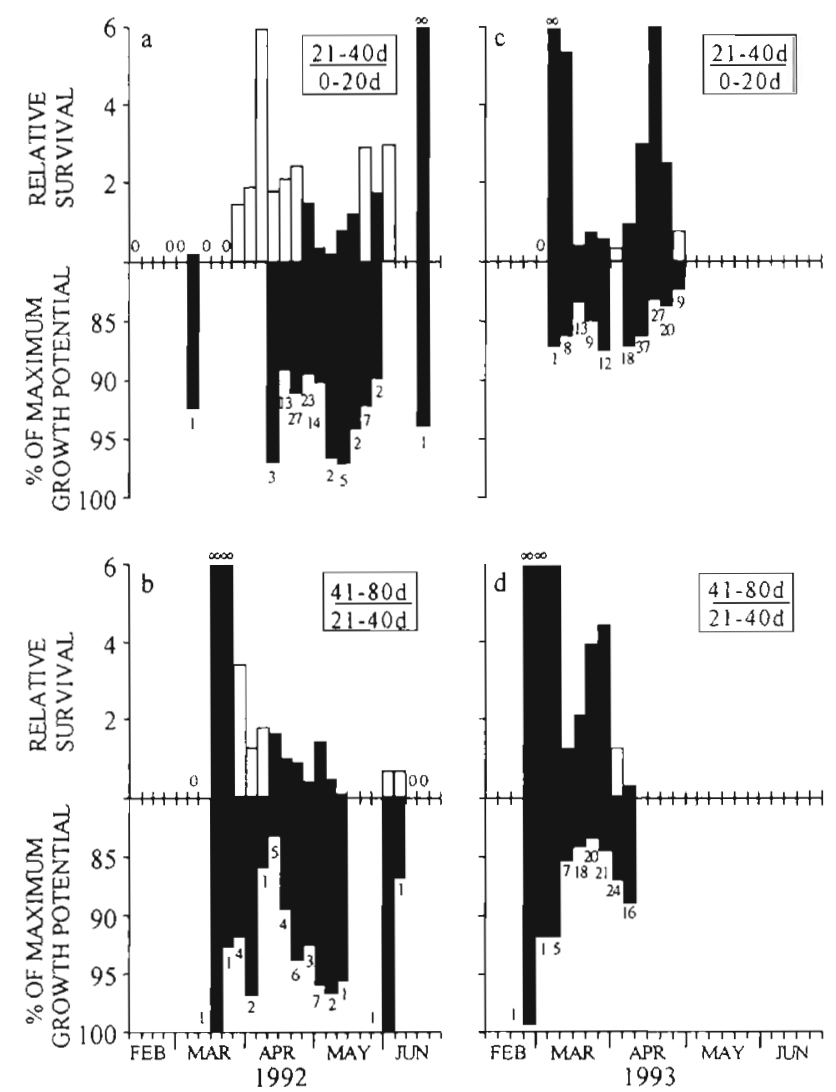

Fig. 11. Melanogrammus aeglefinus. Relative survival (ratio of cohort frequencies in successive age intervals) and average growth performance of $5 \mathrm{~d}$ hatch cohorts of haddock larvae sampled at monthly intervals in 1992 and 1993. Infinite relative survival (cohort present in oldest age interval and absent in youngest) was given a value of 6 and is indicated by $\infty$, Null survival (as opposed to no estimate of survival) is indicated by 0 . Open histograms: estimates of survival in which hatchdate frequencies for the numerator or the denominator or both were interpolated from normal curves fitted to the corrected HFDs (see Figs. 6 \& 7). Average growth performances are for the oldest age interval and are plotted upside down to facilitate comparison with the survival estimates. Number under the histogram represents the number of larvae measured

survival and growth declined from late February to mid March, but minimum growth performance in late March corresponded to relatively good survival.

Combining the observations for 1992 and 1993 indicated that the relative survival of haddock over the 21-40 d and 41-80 d age intervals remained fairly constant or tended to decline with increasing growth performance (Fig. 12a). Relative survival was uncorrelated to growth performance for either age interval ( $\mathrm{p} \geq$ 0.084). Estimates of survival based on the ratio of the normal curves fitted to the HFDs suggested that high relative survival occurred only at high growth performance (Fig. 12c, d).

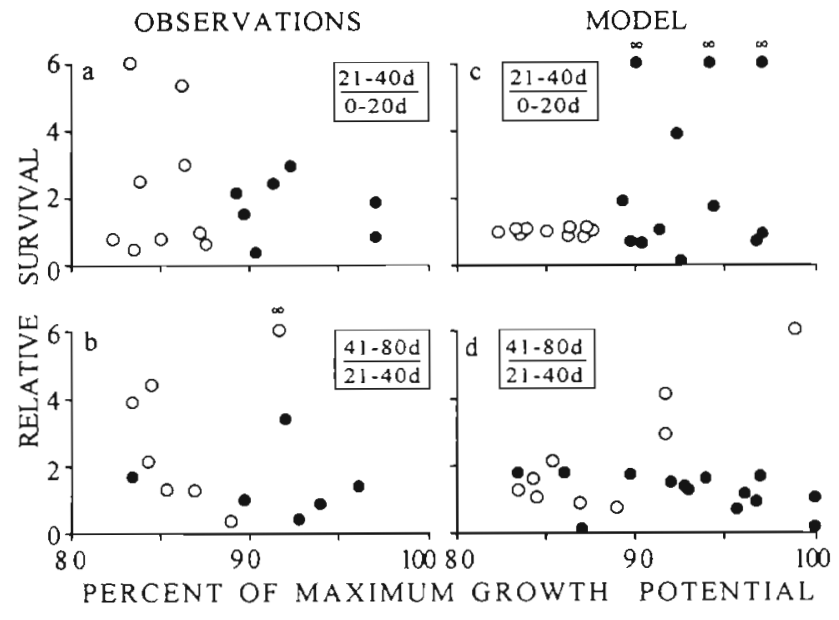

Fig. 12. Melanogrammus aeglefinus. Relative survival between successive age intervals as a function of average growth performance for $5 \mathrm{~d}$ hatch cohorts of pollock larvae sampled at monthly intervals in winter 1992 (0) and 1993 (O). Relative survival was calculated from observed frequencies $(\mathrm{a}, \mathrm{b})$ and from normal curves fitted to the observed frequencies ( $c$, d) (see text). Infinite relative survival (cohort present in oldest age interval and absent in youngest) was given a value of 6 and is indicated by $\infty$. Only those observations

(i.e. cohorts) represented by at least 3 larvae are plotted

\section{DISCUSSION}

\section{Sources of uncertainties in the HFD approach}

While ontogenetic changes in the HFD of young fish can certainly be a powerful tool in the study of early survival and recruitment determination (Campana \& Jones 1992), several sources of uncertainty (aging biases, mortality and dispersion of the larvae, discontinuities in sampling and low sample sizes) may distort HFDs and bias survival estimates. Systematic underestimation of the age of the young fish (i.e. an underestimation proportional to age) will progressively shift HFDs to the right in the ontogenetic sequence, whereas systematic overestimation will shift them to the left. In the present study, gaps (i.e. null frequencies) within the raw HFDs of pollock and haddock larvae for the age intervals $0-20$ and $21-40 \mathrm{~d}$ corresponded well to hatch periods from which larvae of these ages could not materially be captured by our sampling (Figs. $3 \& 4$ ). This result provided an unexpected and interesting confirmation of the general accuracy of the aging procedure for both species. We conclude that the observed shifts in the HFDs during ontogeny generally reflected actual differences in the relative survival of cohorts hatched at different dates

Unless the entire population of larvae is encompassed by sampling, immigration into or emigration 
from the sampling area may bias estimates of larval survival based on the ratio of HFDs. In the present study, we assumed that no immigration of young pollock and haddock onto the banks west of Sable Island occurred (see 'Introduction'). Yet, several instances in which infinite survival was estimated (cohort absent in the HFD of the young age interval and present in the HFD of the older age interval) suggested that older larvae which hatched elsewhere may have recruited onto the banks. Note, however, that infinite survival occurred primarily at the beginning or the end of the hatch season of each species, when sample sizes (number of larvae captured) were low (Figs. 9 \& 11). Although we cannot rule out the potential contribution of immigration of older larvae into the sampling area, we suggest that estimates of infinite survival most often were artefacts that resulted from the scarcity of young larvae at the beginning and end of the hatch season.

As pointed out by Yoklavich \& Bailey (1990), the final shape of the HFD will be influenced by the mortality rate used to correct for the over-representation of late hatchers. These authors reconstructed the respective HFDs of walleye pollock Theragra chalcogramma larvae sampled during 2 separate surveys in May and June-July 1987, and corrected these HFDs using mortality rates at size from the literature (the corrections did not include a dispersion term as sampling encompassed the entire patch of walleye pollock larvae). By comparison, pollock and haddock larvae on the Scotian Shelf were sampled during several sequential monthly surveys and the HFDs were reconstructed for given age intervals irrespective of the survey during which the larvae were captured. For a given age interval (i.e. $0-20,21-40$ and $41-80 \mathrm{~d}$ old), a majority of $5 \mathrm{~d}$ hatch cohorts (but not all) became vulnerable to sampling soon after hatch and before much mortality took place. In other words, for a given age interval, the average age at capture of the larvae representing a $5 \mathrm{~d}$ cohorts varied little over the hatching season and the correction for mortality-dispersion applied to each of these cohort was relatively constant (Figs. 6 \& 7 ). Therefore, correcting for mortality-dispersion did not affect so much the shape of the distribution (skewness) as its height (kurtosis). Campana \& Jones (1992) predicted that this combination of sequential sampling with a mortality correction would produce corrected HFDs in which the mortality correction would be minimized. The estimation of relative survival (e.g. the ratio of the HFDs between 2 successive developmental stages) will be little affected by the flattening of the 2 distributions involved in the calculation.

A weakness of the sequential sampling approach is that, unless the surveys are very close in time, some hatch cohorts will necessarily be non-vulnerable to sampling at some age. While the resulting gaps in the HFDs can provide a valuable test of aging accuracy (see above), they also result in lost information in the seasonal sequence of survival estimates. An obvious solution to avoid gaps is to reconstruct the HFDs for wider age intervals. Yet, wider age intervals reduce the ontogenetic resolution of the analysis. For pollock and haddock on the Scotian Shelf, we selected age intervals $(0-20,21-40$ and $41-80$ d) taking into account this trade-off between the completeness of the HFDs (width of gaps) and the ontogenetic resolution of the analysis. Relative to the frequency of sampling, these age intervals allowed gaps that could be filled with some confidence by fitting normal distributions to the HFDs corrected for mortality. Although estimates of survival for these gaps remain approximations, they followed the seasonal trends in survival relatively well (e.g. Figs. 9a, b \& 11 b).

\section{Growth and survival}

Cushing \& Harris (1973) first proposed that fast growth favours survival by reducing the duration of the planktonic phase during which fish larvae are vulnerable to a suite of predators. The resulting growthpredation hypothesis (Anderson 1988) is a direct offshoot of the match/mismatch hypothesis and has recently achieved the status of paradigm (Bertram 1993. Campana 1996). Although the demonstration of the role of predation in the culling of slow-growing larvae remains elusive, several recent studies generally support the prediction of a link between growth and survival. These can be classified either as longitudinal analyses of size-selective survival based on the individual growth trajectories of the larvae (Post \& Prankevicius 1987, Hovenkamp 1992, Meekan \& Fortier 1996) or as seasonal comparisons of survival and growth in relation to hatchdate (Crecco \& Savoy 1985, Rice et al. 1987).

Despite the sources of uncertainty discussed above, some statistically significant dependence of survival on growth was observed for pollock, especially in the winter 1991-1992, when HFDs were based on reasonable sample sizes and wide variations in growth performance occurred. No convincing dependence of survival on growth performance was found in haddock; a result that may be linked to the small variability in growth performance in this species (Fig. 8). The overall emerging picture is one of low survival at low growth performance and variable survival at high growth performance. High survival at high growth is of course the result predicted by the theory. The unexpected observation of low survival at high growth performance indicates that fast growth is a necessary but 
insufficient condition for survival and suggests that factors other than sub-optimal growth and increased duration of planktonic life can reduce the survival of a cohort. Although we have little grasp on the exact causes of low survival at high growth, 2 nonmutually-exclusive possibilities are suggested by the growth-predation hypothesis. First, increased predation pressure over a given period during the hatching season will increase mortality independently of growth. Because it is nearly impossible to measure, most studies of survival in relation to growth (including this one) assume that predation pressure (the proximal cause of death in the growth-predation hypothesis) is constant for the different cohorts. In the case of pollock and haddock on the Scotian Shelf, it could be argued that winter spawning is an adaptation to reduce predation pressure on the young fish by planktonic predators that may be less abundant in winter. If so, one would expect predation pressure to be higher for cohorts hatched late in the season. Interestingly, low survival at high growth performance (a possible symptom of higher predation pressure) was observed in the later part of the hatching season of pollock and haddock (Figs. 9\& 11).

A second effect of high predation rates predicted by the growth-predation hypothesis is the selective survival of fast growers. Post \& Prankevicius (1987) observed intense selection for fast growers in a slowgrowing cohort of yellow perch Perca flavescens and minimal size-selective mortality in a fast-growing cohort. Meekan \& Fortier (1996) also demonstrated strong selection for fast growth in some (but not all) cohorts of Atlantic cod Gadus morhua on the Scotian Shelf. In the case where intense selection of fast growers occurs, the few survivors will exhibit high growth performance, and low survival will be associated with apparent high growth. Thus, intense predation, selection for fast growth or, more likely, selection for fast growth resulting from intense predation could explain low survival at apparent high growth performance.

The ultimate goal of studies of the link between growth and survival in fish larvae is the early forecasting of survival and year class strength using interannual differences in larval growth as predictors (Campana 1996, Meekan \& Fortier 1996). Based on a series of 5 year classes, Campana (1996) showed a promising relationship between growth during the early pelagic juvenile stage and recruitment in Atlantic cod of Georges Bank. Our results indicate that, in pollock, this correlation between growth and survival may develop during the late larval stage. While the present study generally supports the existence of a strong link between early growth and survival in some cohorts in some years, it also suggests that, during the larval stage, the relationship be- tween fast growth and good survival postulated by the match/mismatch and growth-predation hypotheses may sometime be masked by selection for fast growers under intense predation.

Acknowledgements. Funding for this research was provided by OPEN (Ocean Production Enhancement Network), one of the 15 Networks of Centres of Excellence supported by the Government of Canada through the Natural Sciences and Engineering Research Council of Canada (NSERC). Additional grants from NSERC and Employment and Immigration Canada to L.F. were instrumental in completion of laboratory analyses. The field work could not have been completed without the assistance of our colleagues from McGill and Dalhousie Universities. Special thanks to L. Natanson and L. Michaud for their contribution to this study and to T. Miller for supplying the measurements of larval fish fresh standard length based on video recordings at sea. G. Bergeron, G. Chaumillon, S. Dauchez, J. Michaud, L. Mousseau, A. Potvin, M.-A.Rémillard, M. Simard and A. Villeneuve assisted in the field and/or the laboratory. Contribution to the program of GIROQ (Groupe interuniversitaire de recherches océanographiques du Québec)

\section{LITERATURE CITED}

Amara R, Desaunay Y, Lagardère F (1995) Seasonal variation in growth of larval sole Solea solea (L.) and consequences on the success of larval immigration. Neth J Sea Res 32: $287-298$

Andersen T, Moksness E (1988) Manual for reading daily increments by use of computer program. Flødevigen Meldinger 4:1-36

Anderson JT (1988) A review of size-dependent survival during pre-recruit stages of fishes in relation to recruitment. J Northwest Atl Fish Sci 8:55-66

Bertram DF (1993) Growth, development and mortality in metazoan early life histories with particular reference to marine flatfish. PhD thesis, McGill University

Blaxter JHS (1975) The eyes of larval fish. In: Ali MA (ed) Vision in fishes. Plenum Publishing Corp, New York, p $427-443$

Blaxter JHS (1986) Development of sense organs and behaviour of teleost larvae with special reference to feeding and predator avoidance. Trans Am Fish Soc 115:98-114

Bolz GR, Lough RG (1983) Growth of larval Atlantic cod, Gadus morhua, and haddock, Melanogrammus aeglefinus, on Georges Bank, spring 1981. Fish Bull 81:827-836

Campana SE (1989) Otolith microstructure of three larval gadids in the Gulf of Maine, with inferences on early life history. Can J Zool 67:1401-1410

Campana SE (1996) Year-class strength and growth rate in young Atlantic cod Gadus morhua. Mar Ecol Prog Ser 135: $21-26$

Campana SE, Jones CM (1992) Analysis of otolith microstructure data. In: Stevenson DK, Campana SE (eds) Otolith microstructure examination and analysis. Can Spec Publ Fish Aquat Sci 117:73-100

Chaumillon G, Fortier L (in press) Feeding success of flatfish larvae in relation to retention on Emerald, Western and Sable Island banks (Scotian Shelf). Can J Fish Aquat Sci

Checkley DM Jr, Raman S, Maillet GL, Mason KM (1988) Winter storm effects on the spawning and larval drift of a pelagic fish. Nature 335:346-348 
Crecco VA, Savoy TF (1985) Effects of biotic and abiotic factors on growth and relative survival of young American shad, Alosa sapidissima, in the Connecticut River. Can J Fish Aquat Sci 42:1640-1.648

Cushing DH (1990) Plankton production and year-class strength in fish populations: an update of the match/mismatch hypothesis. Adv Mar Biol 26:142-155

Cushing DH, Harris JGK (1973) Stock and recrultment and the problem of density dependence. Rapp P-V Reun Cons It Explor Mer 164:142-155

Gagné JA, O'Boyle RN (1984) The timing of cod spawning on the Scotian Shelf. In: Dahl E, Danielssen D, Moksness E, Solemdal P (eds) The propagation of cod. Flodevigen Rapp 1:501-518

Healey $\mathrm{MC}$ (1982) Timing and relative intensity of size-selective mortality of juvenile chum salmon (Oncorhynchus keta) during early sea life. Can J Fish Aquat Sci 39: 952-957

Hjörleifsson E, Klein-MacPhee G (1992) Estimation of live standard of winter flounder Pleuronectes americanus larvae from formalin-preserved, ethanol-preserved and frozen specimens. Mar Ecol Prog Ser 82:13-19

Hovenkamp F (1992) Growth-dependent mortality of larval plaice Pleuronectes platessa in the North Sea. Mar Ecol Prog Ser 82:95-101

Kimura DK (1977) Statistical assessment of the age-length key. J Fish Res Board Can 34:317-324

Meekan M. Fortier L (1996) Selection for fast growth during the planktonic life of Atlantic cod Gadus morhua on the Scotian Shelf. Mar Ecol Prog Ser 137:25-37

Methot RD Jr (1983) Seasonal variation in survival of larval northern anchovy, Engraulis mordax, estimated from the age distribution of juveniles. Fish Bull 81:741-750

Moksness E, Fossum P (1992) Daily growth rate and hatching date distribution in Norwegian spring-spawning herring (Clupea harengus). ICES J Mar Sci 40:217-221

Editorial responsibility: Otto Kinne (Editor), Oldendorf/Luhe, Germany
Nyman RM, Conover DO (1988) The relation between spawning season and the recruitment of young of the year bluefish, Pomotomus saltatrix, to New York. Fish Bull 86 $237-250$

O'Boyle RN. Sinclair M, Conover RJ, Mann KH, Kohler AC (1984) Temporal and spatial distribution of ichthyoplankton communities of the Scotian Shelf in relation to biological hydrological, and physiographic features. Rapp P-V Réun Cons Int Explor Mer 183:27-40

Post JR, Prankevicius AB (1987) Size-selective mortality in young-of-the-year yellow perch (Perca flavescens): evidence from otolith microstructure. Can J Fish Aquat Sci 44:1840-1847

Radtke RL, Waiwood KG (1980) Otolith formation and body shrinkage due to fixation in larval cod (Gadus morhua). Can Tech Rep Fish Aquat Sci 929:1-10

Rice JA, Crowder LB, Holey ME (1987) Exploration of mechanisms regulating larval survival in Lake Michigan bloater a recruitment analysis based on characteristics of individual larvae. Trans Am Fish Soc 116:703-718

Sutcliffe WH, Loucks RH, Drinkwater KF (1976) Coastal circulation and physical oceanography of the Scotian Shelf and the Gulf of Maine. J Fish Res Board Can 33:98-115

Suthers IM, Frank KT (1989) Inter-annual distributions of larval and pelagic juvenile cod (Cadus morhua) in southwestern Nova Scotia determined with two different gear types. Can J Fish Aquat Sci 46:591-602

Thimijan RW, Heins RD (1983) Photometric, radiometric, and quantum light units of measure: a review of procedures for interconversion. HortScience 18:818-822

Victor BC (1983) Recruitment and population dynamics of a coral reef fish. Science 219:419-420

Yoklavich MM, Bailey KM (1990) Hatching period, growth and survival of young walleye pollock Theragra chalcogramma as determined from otolith analysis. Mar Ecol Prog Ser 64:13-23

Submitted: April 9, 1998; Accepted: July 31, 1998 Proofs received from author(s): October 27, 1998 